\title{
Maternal and paternal expectations of antenatal education across the transition to parenthood
}

\section{Abstract}

This study uses research evaluation data to explore parents' expectations from antenatal classes as they transition from pregnancy to the post-natal period. Understanding parents' expectations over this time with respect to knowledge and skills provides an opportunity to tailor antenatal classes more closely to the needs of parents. Equally, it is important to understand, if, and how, these expectations are met during the transition to parenthood. Understanding parents expectations of antenatal classes, and exploring the value of classes amongst attendees has the potential to result in improved attendance, reduced dropout rates and overall greater satisfaction. This paper, which explores whether a programme of antenatal classes meets parents expectations across the transmission to parenthood adds to the existing body of research about the preparation needs of parents in early parenthood.

Keywords: Expectations; fathers; mothers; preparation; education; antenatal classes, childbirth

Key points: Pregnancy and birth is considered a 'critical opportunity' to affect great change, when parents are receptive to information and advice.

There is a growing emphasis on the importance of meeting the needs of partners/fathers to be, and this can be challenging.

Women are keen to understand more about creating a closeness to the baby, to make new friendships with other women, and to facilitate positive emotional wellbeing.

Fathers to be are less specific in the articulation of their needs and expectations from antenatal education.

This document is the Accepted Manuscript version of a Published Work that appeared in final form in British Journal of Midwifery, copyright (C) MA Healthcare, after peer review and technical editing by the publisher. To access the final edited and published work see https://doi.org/10.12968/ bjom.2019.27.4.235. 


\section{BACKGROUND}

Supporting parents-to-be through antenatal education classes has been recognised as an important prevention and intervention strategy (Department of Health 2011). Key policy documents highlight the need for pregnant women to be offered opportunities to attend participant-led antenatal classes (NICE 2008), and in recent years, there has been an increasing expectation for men to play a more active role in childbirth and preparation for parenting. A reviewed commissioned by the Department of Health $(\mathrm{DoH})$ and undertaken by Schrader et al (2009) identified gaps in provision and areas for improvement, in order to make classes more engaging and to meet the requirements of today's expectant parents.

A number of antenatal education programmes have been developed over the last few decades. A variety of approaches and models exist with generic key features (Jaddoe 2009). Despite a growing interest in how best to suit the needs of parents-to-be with respect to antenatal education, there is still a concern that antenatal education may not be meeting the needs and expectations of parents-to-be, particular fathers. Findings from a large Swedish study to assess parent's expectations of antenatal education indicate that an increased focus on preparation for parenthood was what expectant parents most want from classes (Ahlden et al (2012). Smythe et al (2015), reflecting on the findings from a literature review on the effectiveness of antenatal education preparation on father's transition to parenthood, suggests that the traditional focus of antenatal education upon the needs of expectant women has led to the specific needs of fathers in the antenatal education context being overlooked. Findings by Palsson et al (2017) in a study of first time fathers experiences of antenatal preparation in relation to the challenges met in early parenthood reveal that preferences varied for fathers with respect to structure, and delivery, with some fathers were concerned about the environment not being conducive to 'opening up'. On the whole the fathers in this study wanted clear and honest information about the realities of life with a new baby (Palsson et al 2017). Despite the growing evidence base, from which the content and the delivery style of antenatal education can draw from, there are still gaps in knowledge about what parents-to-be expect from classes, and what they consider valuable.

This paper addresses some of the gaps, and outlines what parents expected, and found most valuable from attendance to an antenatal nurturing programme. Findings from this study provide insight into the expectations and learning needs of parents-to-be, as they make the transition through pregnancy into the early weeks and months of parenthood. 
Ethical approval to undertake the study was granted by the faculty of Health and Social Care Research Ethics Committee at the University of Hull.

\section{METHOD}

This paper is based on data collected by open ended questions, with a sample of expectant parents who were transitioning from pregnancy to parenthood and attending an 8 week pre-birth programme delivered by Family Links. The aim of the overall study was to evaluate the effectiveness of an antenatal parenting programme delivered by Family Links. The programme, called Welcome to the World (WTTW), is an 8-week programme designed to help parents prepare for childbirth and parenthood. Sessions are focused upon improving attunement and bonding, facilitating parental wellbeing, improving skills in breastfeeding and improving practical care of the baby.

The field work took place between August 2015 and September 2016. Localities for inclusion in the evaluation were Armagh, Coventry, Bingley, Bristol, Cookstown, Stanley, Bridlington, Barry, Caterham, Allerton, Creggan, Bradford, Liverpool, and Cwmbran. Sampling used a purposive design to recruit participants best suited to provide meaningful data. Attendees of the WTTW programme were the sample for the study. Attendees who were registered for the programme were sent an information leaflet about the evaluation with the pre-programme information pack by the parent group leader who would be delivering the programme. They were informed of their right not to take part of the evaluation, and that this would not affect their attendance on the programme. They were asked in an introductory session if they had the information leaflet and if they wished to take part. If so, they were consented for data collection.

\section{Data collection}

This paper reports on the findings from open ended questions about the expectations that parents-to-be had in relation to the programme content, and whether or not their expectations had been met. Parents-to-be completed the open ended questions at 2 time points in pregnancy, and once during the post-natal period;

Timepoint 1 (T1): the introductory session (in the $2^{\text {nd }}$ trimester of pregnancy)

Timepoint 2 (T2): the final session (in the third trimester of pregnancy)

At Timepoint 3 (T3), the re-union session (3-4 months after the birth of the baby). 
[Type here]

\section{Data analysis}

Answers to the open ended questions were coded and analysed manually to identify core themes (Braun and Clarke, 2006). The overall research question which guided the analysis of the T1 data was

"What are the expectations of parents attending an antenatal nurturing programme?"

The question guiding the analysis of the T2 and T3 data was as follows;

"Which aspects of the programme were most valuable across the transition to parenthood?"

Data were searched to find repeated patterns of meaning, and issues of interest in relation to the research question. Labels were applied to important features within the data which were relevant to the overall questions, codes were used to capture relevant concepts which emerged from the labelling process. Every data item was coded, all codes and relevant data extracts were collated (Braun and Clarke, 2013). Coded data were searched for similarities, and where similarities were found and agreed on, the data was used to construct relevant themes. Two researchers independently identified the core themes. The researchers met and reviewed the essence of the themes for their clarity in relation to the research questions; the authors debated the relevance of the themes to the overall 'story' about the data, and proceeded to name the themes appropriately.

Trustworthiness of the study was promoted by carefully monitoring the research process. Two researchers analysed the data independently. The final themes were identified through discussion (Jeanfreau and Jack, 2011). Credibility was maximised through repeat contact with previous participants of WTTW, and was enhanced through discussion of the emergent themes.

Questionnaires were completed by 131 participants (96 women, 35 men) from 17 WTTW groups in 13 locations across the UK; however, only 54 (43 women, 11 men) completed them at all three time points. 
[Type here]

Table 1: Summary of participant information

\begin{tabular}{lc} 
& $\begin{array}{c}\text { Participants who } \\
\text { completed T1, T2 and } \\
\text { T3 } \\
\text { (n=54) }\end{array}$ \\
\hline Demographic characteristics & \\
\hline Women (\%) & 79.6 \\
Married or living with partner & 90.7 \\
(\%) & \\
Paid employment (\%) & 81.5 \\
Parity: & 75.9 \\
Fecond baby (\%) & 9.3 \\
Third (or more) baby & 11.1 \\
(\%) & 29.0 \\
Age (mean, years) &
\end{tabular}




\section{FINDINGS}

\section{Needs and expectations of women: relationships}

Across the data there are a number of interesting features to observe in the data from women; firstly, of key importance to women was developing relationships, and this featured regularly across the three time points; specifically, relationships with the baby, with other attendees, and to a lesser extent with their partners. Most evident across the T1 data for women was their need to learn more about the relationship with the baby, whilst it was still in utero and after birth. Women were keen to gain knowledge about how to develop their relationship and the best ways in which this could be facilitated. In particular, they were keen to understand more about creating a closeness to the baby before birth, and bonding and attachment before and after birth. Some of the responses to the question around expectations $\mathrm{T} 1$ are detailed below;

"Knowledge re. Baby's development + interacting with baby" (GR05033 TP1)

"Gain more knowledge about different ways to bond + deal with having a baby" (EN16109 TP1)

In addition, at T1, women anticipated that the classes would be a good platform to form friendships with other attendees. They expected the course to provide them with a place that they could share worries, meet and gain experience from others and make friends.

"To make new friends who are also first time mothers" (WA08054 TP1)

"Meet people in the same situation" (EN11079 TP1)

"Meeting people" (EN14094 TP1)

"New friends for me \& my baby" (EN16111 TP1)

At T2 and T3, women felt that this need to develop their relationship with their baby had been satisfied;

"I feel it helped me bond with my baby prior to birth \& open discussion with my husband on certain topics prior to birth" (GR01002 TP3)

"I loved the nurturing aspect, it was outstanding" (EN11075 TP2) 
[Type here]

There was also a sense that attendance to the classes addressed their need to meet and connect with other attendees;

"Yes, great support and friendship and a comfortable environment to share concerns

- safe!" (GR01001 TP2)

"Yes it has been lovely meeting other expectant mums" (GR01005 TP2)

"I met some wonderful women" (EN11075 TP2)

"Everyone I met lovely friendly" (GR12086 TP2)

"Met some lovely people" (EN14098 TP2)

\section{Needs and expectations of women: emotional wellbeing}

Other aspects which were important for women to understand about were facilitating positive emotional wellbeing. For women, addressing emotional and mental health needs was also significant at this time. Data highlights that women expected their engagement with WTTW to reduce their anxieties, and to increase their confidence, alongside providing an increased ability to 'cope', and feelings of reassurance.

"More understanding of the thoughts and feelings of pregnancy. Am I normal in what I feel etc" (EN04019 TP1)

"Learn about emotions" (WA17118 T1)

"To be less anxious and more confident about when the baby arrives" (EN04029 TP1)

At T2 and T3, data suggests that for a number of women, emotional wellbeing was facilitated through the classes.

"Yes very much so. Normalised fears. Helped self mentally prepare" (GR01004 TP2)

"It has been very informative and has helped me cope with the emotional preparation for birth and becoming a mum" (WA08054 TP2)

"Was a great course, really helped us prepare for parenthood. Covered more topics than I expected. Emotional + practical support" (EN03013 TP3) 


\section{Needs and expectations of women: practical knowledge and advice}

Also, but to a lesser extent was the need for a degree of practical advice; particularly with respect to breastfeeding and in the early days of looking after a newborn baby, being in labour, and giving birth.

"Better skills of hands on things (bathing)" (EN03014 TP1)

“Learn about breastfeeding” (EN10067 TP1)

"To learn more about caring, feeding, \& baby needs" (EN10067 TP1)

New mums felt that this aspect of the course extremely helpful for them in the days and weeks after birth.

"It provided a safe environment to prepare myself for the new baby, particularly feeding" (GR01001T3)

"Definitely. Just the information on breastfeeding, bathing, communication, breathing through (GR05039 TP3)

"Just the information on breastfeeding, bathing, communication, breathing through labour. It was all very useful to be during my pregnancy and early weeks of parenthood" (GR05039 TP3)

"The course was really helpful in helping me prepare for having a baby. It was very informative. I particularly liked the sessions with the midwives - labour day \& breastfeeding were particularly helpful" (WA08054 T3)

"The course was positively helpful on the sections to do with bonding, labour and feeding" (GR01001T3)

The needs and expectations of men: generalized knowledge gain and preparation for parenthood

Across the data, men's specific needs and expectations are difficult to capture. They are less specific in the articulation of their needs and expectations from antenatal education. Similar to the study by Palsson et al (2017), our study highlights that fathers seem to have difficulties in knowing what they need to know. At T1, data indicates that for partners $(n=11)$, 
all of whom were male, expectations were vague, and more general. Data highlights that for this set of fathers to be, the classes were seen as a place to

"Learn a bit more knowledge" (EN04028 TP1)

"To learn new things" (GR05040 TP1)

"Gain new tips" (EN04023 TP1)

"Learn things we haven't thought of yet" (EN10068 TP1)

'Learn the 'baby basics' (EN14093 TP1)

"Gain an understanding of what to expect" (GR12084 TP1)

Partner's data at T2 confirms that the course had met their expectations, and that the valuable aspects of learning were aligned to expectations from T1; generalised knowledge gain and how to support their partners. In addition to this, by T2, men had understood that hands on practical skill development was of value. There was a shift from a quest for non-specific and at times vague aspects of knowledge gain, and by T3 the most valuable aspects of the programme were the practical skills they had learnt in order to provide hands on care and the support networks. Despite this shift, there were still some aspects of their learning that remained vague such as a 'generalised knowledge gain'. Table 2 below captures the general needs and expectations of both men and women and compares these across the 3 time points.

\section{Table 2: Table of Findings}

\begin{tabular}{|c|c|c|c|c|c|}
\hline \multicolumn{2}{|c|}{$\begin{array}{l}\text { What are the expectations } \\
\text { of parents attending an } \\
\text { antenatal nurturing } \\
\text { programme? }\end{array}$} & \multicolumn{4}{|c|}{$\begin{array}{l}\text { Which aspects of the programme were most valuable across the tran } \\
\text { to parenthood? }\end{array}$} \\
\hline $\begin{array}{l}\text { Women } \\
(n=43)\end{array}$ & $\begin{array}{c}\text { Partners } \\
(n=11)\end{array}$ & $\begin{array}{l}\text { Women } \\
(n=43)\end{array}$ & $\begin{array}{c}\text { Partners } \\
(n=11)\end{array}$ & $\begin{array}{l}\text { Women } \\
(\mathrm{n}=43)\end{array}$ & $\begin{array}{c}\text { Partners } \\
(\mathrm{n}=11)\end{array}$ \\
\hline T1 & T1 & T2 & T2 & T3 & T3 \\
\hline $\begin{array}{l}\text { The } \\
\text { developing } \\
\text { relationship } \\
\text { with the } \\
\text { baby } \\
\text { Forming } \\
\text { supportive }\end{array}$ & $\begin{array}{l}\text { Knowledge } \\
\text { gain } \\
\text { Preparation }\end{array}$ & $\begin{array}{l}\text { Learning how to } \\
\text { connect with the } \\
\text { baby } \\
\text { Establishing a } \\
\text { supportive } \\
\text { network }\end{array}$ & $\begin{array}{l}\text { Knowledge } \\
\text { gain } \\
\text { Preparation } \\
\text { Learning how } \\
\text { to support } \\
\text { partner }\end{array}$ & $\begin{array}{l}\text { Learning how to } \\
\text { connect with the } \\
\text { baby } \\
\text { Making friends } \\
\text { and establishing } \\
\text { a supportive } \\
\text { network }\end{array}$ & $\begin{array}{l}\text { Knowledge } \\
\text { gain } \\
\text { Preparation } \\
\text { Learning } \\
\text { practical skills } \\
\text { to care for the } \\
\text { baby }\end{array}$ \\
\hline
\end{tabular}




\begin{tabular}{|c|c|c|c|c|}
\hline $\begin{array}{l}\text { links with } \\
\text { others } \\
\text { Facilitating } \\
\text { positive } \\
\text { emotional } \\
\text { wellbeing } \\
\text { Knowledge } \\
\text { and skills } \\
\text { about } \\
\text { practical } \\
\text { aspects } \\
\text { (feeding, } \\
\text { labour and } \\
\text { birth) }\end{array}$ & $\begin{array}{l}\text { Nurturing family } \\
\text { relationships } \\
\text { Understanding } \\
\text { and addressing } \\
\text { emotional well- } \\
\text { being } \\
\text { Developing vital } \\
\text { practical skills } \\
\text { with respect to } \\
\text { breastfeeding } \\
\text { and labour and } \\
\text { birth } \\
\text { Gaining } \\
\text { confidence at } \\
\text { parenting }\end{array}$ & $\begin{array}{l}\text { Learning the } \\
\text { practical skills }\end{array}$ & $\begin{array}{l}\text { Nurturing family } \\
\text { relationships } \\
\text { Understanding } \\
\text { and addressing } \\
\text { emotional well- } \\
\text { being } \\
\text { Developing vital } \\
\text { practical skills } \\
\text { with respect to } \\
\text { breastfeeding } \\
\text { and labour and } \\
\text { birth } \\
\text { Gaining } \\
\text { confidence at } \\
\text { parenting }\end{array}$ & $\begin{array}{l}\text { Developing } \\
\text { vital support } \\
\text { networks }\end{array}$ \\
\hline
\end{tabular}

\section{DISCUSSION}

The data from this study form one part of an evaluation of WTTW classes; no claims are being made as to the wider transferability of the findings. The analysis set out to provide insight into the expectations, learning needs and the valuable aspects of antenatal education, as parents-tobe make the transition through pregnancy into the early weeks and months of parenthood. This data highlights a number of interesting aspects, which act as a point of discussion with respect to calls for antenatal education to be more attractive and engaging.

The transition to parenthood is an important time for parents as they learn how to cope with their new roles and responsibilities. Of equal importance is the fact that pregnancy and birth is considered a 'critical opportunity' to affect great change, when parents are especially receptive to offers of advice and support. Antenatal education programmes such as WTTW are accessible to parents-to-be, by either self-referral, or referral through locally agreed arrangements. The focus of the programme being that of attunement, bonding and emotional wellbeing, it demonstrates a responsiveness to the importance of the 1001 critical days manifesto set out by the Government in 2015. 
A number of studies have highlighted a need for improvements in antenatal classes to meet the requirements of expectant parents (Deave et al 2008, Billingham 2011, Ahlden, et al 2012, Gilmer et al 2016, Entsieh et al 2016). For expectant mothers in this study, their expectations and learning needs were clear and articulated and could be grouped easily into three overarching topics/aspects of transitioning to parenthood; 'Developing relationships (with baby, friends, and family)', 'Emotional wellbeing', and 'Practical aspects'. These remained fairly consistent across all time points. Women were satisfied that their needs were met with respect to the three dominant aspects; this is reassuring for the WTTW providers. Data from women illustrates that they have a strong awareness of the value of learning about both the physical and emotional aspects of parenthood, the baby's wellbeing, and healthy social and emotional development.

Meeting the needs of partners/fathers on the other hand appears to be more challenging. Smyth et al (2015) highlight the importance of helping fathers to understand how they can support their partners during pregnancy, labour and birth, and to prepare them for parenthood. Maternity services are being urged to expand their notion of appropriate preparation of parenthood to include fathers. In response to this, there is a now substantial body of evidence to show that father's engagement with antenatal education is improving. Despite these improvements, research suggests that fathers continue to feel frustrated by their lack of inclusion in maternity care, and the absence of available targeted information (Deave et al 2008, StGeorge and Fletcher 2011, Smythe et al 2015).

Encouraging attendance and including fathers-to-be in discussions about learning needs is vital to ensure they feel included however, the data from our study suggests that by asking fathers what they would like to learn, or what they consider to be most valuable doesn't seem to help tailor the classes to their needs. The data from this study indicates that many fathers-to-be don't appear to know what they want to know. This reflects previous research by Pallson et al (2017) where fathers identified that their lack of previous experience created difficulties for them in knowing what they might need to know and forming questions. The differences between fathers and mothers learning needs may reflect, as Draper (2003) points out the traditional stereotypes, framed by hegemonic masculinity, which over previous decades have clearly differentiated men and women's parenting roles. Whilst, the data portrays fathers as less engaged, and less aware of their social and emotional needs, it might be that this is more a reflection of the structure of the classes being less conducive to them articulating their needs; consequently fathers are playing out their 'strong' and silent' stereotypes. 
Interestingly, whist the fathers in this evaluation seemed generally happy with their levels of preparedness for parenting, the data reflects a degree of vagueness in terms of fathers being aware of their learning needs or, the very least, a reluctance to articulate those needs. One aspect of this evaluation which has provided a platform for further exploration of men's engagement with classes has been the differences in the learning needs between expectant fathers and mothers. It would seem that by inviting fathers-to-be into antenatal education, and asking them to identify their learning needs, is not an appropriate method of gaining meaningful information to tailor antenatal education to the needs of fathers. What is noteworthy in this data is that for some men, specificity of learning needs may increase as pregnancy progresses, and increasing proximity to delivery may be associated with an ability to formulate more relevant learning needs and expectations based on increased knowledge gain. This may also be facilitated by increased familiarity with the group, the environment and the overall process of antenatal preparation, so as father-to-become more comfortable with the classes, and more familiar with other attendees, they are able to consider their needs in a more focused and meaningful way. It is important to state at this point that we are not presenting this as a universal experience for all fathers-to-be attending parenting education classes, rather, our intention is to demonstrate one approach to providing a greater understanding of the needs of fathers.

Recent research indicates that fathers-to-be do require something different from what is currently on offer. Whilst previous research suggests that fathers felt frustrated with the lack of relevant information and lack of tailored preparation for fatherhood, more recent research indicates that fathers in early fatherhood, reflecting on their needs during pregnancy, would have benefitted from guidance towards creating a fatherhood identity, and finding information about reliable websites. This helps fathers undertake their own information seeking and whilst being confident their sources were accurate (Palsson et al 2017); this strategy of seeking their own information may also be more aligned to their perceived needs to be the 'provider' and the 'protector'; they are providing the family unit with vital information, and at the same time, they are protecting the unit from potentially harmful (unreliable) information. The creation of spaces (physical or virtual) where groups of fathers can informally share information has been identified as an important aspect of preparation for parenthood and the early days and weeks after childbirth (StGeorge and Fletcher 2011). Finally, recognizing and providing strategies for times of role conflict, where fathers feel conflicted about being both the breadwinner and the nurturer was identified as an important aspect of preparing fathers for the transition to parenthood (StGeorge and Fletcher 2011). 


\section{Conclusion}

Antenatal classes such as WTTW offer a unique opportunity for parents-to-be to express their feelings and expectations of parenting, and to be able to align these to their learning needs. This evaluation set out to uncover parents' expectations of WTTW classes with respect to knowledge and skills, with the aim of providing Family Links with an opportunity to tailor antenatal classes more closely to the needs of parents. Research on the needs of fathers in antenatal education is growing, and the findings from this evaluation contribute to this body of work. Findings indicate that both sets of parents have quite different learning needs at different times, and that whilst expectant mothers are clear about what they want to know from classes, fathers enter classes with unspecific learning needs, which become slightly more focused as pregnancy progresses, but generally speaking, remain fairly vague. This might not be a problem, however, it is an interesting finding. Further, it is unclear why in fathers-to-be, increasing proximity to delivery seems to be associated with an ability to formulate more specific learning needs and expectations. In attempt to address concerns that antenatal education may not be meeting the needs and expectations of fathers, this finding, alongside findings from the growing body of research on fathers and parenting, is worthy of further exploration and could help providers plan new strategies for engaging men in more meaningful ways.

\section{References}

Ahlden, I., Ahlehagan, S., Dahlgren, L.O., Josefsson, A. (2012) Parent's expectations about participating in antenatal parenthood education classes. The Journal of Perinatal Education, $21(1), 11-7$.

Bergstrom, M., Kieler, H., Waldenstrom, U. (2011) A randomised controlled multicentre trial of women's and men's satisfaction with two models o antenatal education. Midwifery, 27, $195-200$.

Billingham, K. (2011) Preparing for parenthood: the role of antenatal education. Community Practitioner, 84 (5), 36 - 38.

Braun, V., Clarke, V. (2006) Using thematic analysis in psychology. Qualitative Research in Psychology, 3, $77-101$.

Deave, T., Johnson, D., Ingram, J. (2008) Transition to parenthood: the needs of parents in pregnancy and early parenthood. BMC Pregnancy Childbirth, 8, 30, 1- 11.

Department of Health. (2011) Preparation for birth and beyond. Available online at https://assets.publishing.service.gov.uk/government/uploads/system/uploads/attachment d ata/file/215386/dh 134728.pdf [accessed July 2017]. 
Draper, J. (2003) Men's passage to fatherhood: an analysis of the contemporary relevance of transition theory. Nurse Inquiry, 10 (1), $77-77$.

Entsieh, A.A., Hallstrom, I.K. (2016) First time parents' prenatal needs for early parenthood preparation - A systematic review and meta-synthesis of qualitative literature. Midwifery, 39, $1-11$.

Gilmer, C., Buchan, J., Letourneau, N., Bennett, C., Shanker, S.G., Fenwick, A., Smith-Chant, B. (2016) Parent education interventions designed to support the transition to parenthood: A realist view. International Journal of Nursing Studies, 59,118 - 133.

Jaddoe, V.W. (2009) Antenatal education programmes: do they work? Available on line at https://www.thelancet.com/journals/lancet/article/PIIS0140-6736(09)61610-

X/abstract?code=lancet-site [accessed July 2017].

Jeanfreau, S.G., \& Jack, L. (2011). Appraising qualitative research in health education: guidelines for public health educators. Health Promotion Practitioner, 11, 612 - 617 .

National Institute for Health and Care Excellence. (NICE). (2008) Antenatal care for uncomplicated pregnancies. Available online at https://www.nice.org.uk/guidance/cg62/chapter/1-guidance [accessed July 2017].

White, E.F., Grey, G.H., Pink I.J. (2007) Getting the facts right. Journal of Education, 99 (34), 55-59.

StGeorge, J.M., Fletcher, R.J. (2011) Fathers online: Learning about fatherhood through the internet. The Journal of Perinatal Education, 20 (1), $154-162$.

Smythe, S., Spence, D., Murray, K. (2015) Does antenatal education prepare fathers for their role as birth partners and for parenthood. British journal of Midwifery, 23 (5), 36 - 42.

\section{Reflective questions}

What are the challenges facing providers of antenatal education when it comes to fathers and partners?

How well does antenatal education/preparation for parenthood engage fathers and partners?

What are the benefits to greater engagement of fathers and partners in antenatal education/preparation for parenthood? 
[Type here] 